\title{
Diagnosing Acute Coronary Syndrome: A Challenge for General Practitioners and Cardiologists
}

Citation for published version (APA):

Willemsen, R. T. A., Kietselaer, B. L. J. H., Kusters, R., Buntinx, F., Glatz, J. F. C., \& Dinant, G. J. (2015). Diagnosing Acute Coronary Syndrome: A Challenge for General Practitioners and Cardiologists. Emergency Medicine, 5(2), [1000242]. https://doi.org/10.4172/2165-7548.1000242

Document status and date:

Published: 01/01/2015

DOI:

10.4172/2165-7548.1000242

Document Version:

Publisher's PDF, also known as Version of record

Document license:

Taverne

Please check the document version of this publication:

- A submitted manuscript is the version of the article upon submission and before peer-review. There can be important differences between the submitted version and the official published version of record.

People interested in the research are advised to contact the author for the final version of the publication, or visit the DOI to the publisher's website.

- The final author version and the galley proof are versions of the publication after peer review.

- The final published version features the final layout of the paper including the volume, issue and page numbers.

Link to publication

\footnotetext{
General rights rights.

- You may freely distribute the URL identifying the publication in the public portal. please follow below link for the End User Agreement:

www.umlib.nl/taverne-license

Take down policy

If you believe that this document breaches copyright please contact us at:

repository@maastrichtuniversity.nl

providing details and we will investigate your claim.
}

Copyright and moral rights for the publications made accessible in the public portal are retained by the authors and/or other copyright owners and it is a condition of accessing publications that users recognise and abide by the legal requirements associated with these

- Users may download and print one copy of any publication from the public portal for the purpose of private study or research.

- You may not further distribute the material or use it for any profit-making activity or commercial gain

If the publication is distributed under the terms of Article $25 \mathrm{fa}$ of the Dutch Copyright Act, indicated by the "Taverne" license above, 


\title{
Emergency Medicine: Open

\section{Diagnosing Acute Coronary Syndrome: A Challenge for General Practitioners and Cardiologists}

Robert TA Willemsen ${ }^{1 *}$, Bas LJH Kietselaer ${ }^{2}$, Ron Kusters ${ }^{3,4}$, Frank Buntinx $^{1,5}$, Jan FC Glatz ${ }^{6}$ and Geert Jan Dinant ${ }^{1}$

${ }^{1}$ Department of Family Medicine, Maastricht University, Netherlands

${ }^{2}$ Department Cardiology and Radiology, Maastricht University Medical Centre, Netherlands

${ }^{3}$ Department Clinical Chemistry and Hematology, Jeroen Bosch Hospital, Netherlands

${ }^{4}$ MIRA Institute for Biomedical Technology and Technical Medicine, Netherlands

${ }^{5}$ Department General Practice, Catholic University Leuven, Netherlands

${ }^{6}$ Department of Genetics and Cell Biology, Maastricht University, Netherlands

*Corresponding author: Robert TA Willemsen, Department of Family Medicine, Maastricht University, PO box 616 , 6200 MD Maastricht, Netherlands, Tel: +31(0)433882302; E-mail: robert.willemsen@maastrichtuniversity.nl

Received date: January 21, 2015; Accepted date: February 09, 2015; Published date: February 16, 2015

Copyright: ( $) 2015$ Willemsen RTA, et al. This is an open-access article distributed under the terms of the Creative Commons Attribution License, which permits unrestricted use, distribution, and reproduction in any medium, provided the original author and source are credited.

\begin{abstract}
Three patients present with chest pain to their general practitioner. In all three cases, the patient is suspected of acute coronary syndrome (ACS). In the first case, a coronary artery disease causing the complaints is ruled out since troponin levels remain within the normal range. In the second case, troponin is elevated due to non STelevated myocardial infarction. In the third case, troponin is elevated due to cardiac cell damage in severe pneumonia (i.e. cardiac damage is not caused by a coronary artery occlusion).

In cardiology, diagnostic tools for ruling ACS in or out are becoming increasingly sensitive. In general practice, diagnostic means to discriminate between ACS and less severe causes of chest complaints remain poor. Both situations challenge physicians working in their respective fields. Cardiologists must deal with a decrease in testing specificity due to the increasing analytical sensitivity of high-sensitivity troponin, and face the dilemma of whether or not to perform invasive coronary angiography in cases of doubt. General practitioners are still lacking adequate diagnostic tools. These difficulties are illustrated in three cases where patients' present chest complaints in primary care and are eventually referred to a cardiologist. Notwithstanding the presence of the aforementioned dilemmas, combining clinical reasoning with current definitions of ACS and myocardial infarction leads to an unambiguous diagnosis in all three cases.
\end{abstract}

Keywords: General practice; Cardiology; Primary care; Secondary care; Chest pain; Acute coronary syndrome; Myocardial infarction; Diagnostic tools; Biomarkers

\section{Learning Points}

Discriminating between ACS and less severe causes of chest pain remains difficult for a GP.

An elevated plasma troponin value is strongly indicative of myocardial damage. However, myocardial damage has multiple causes beyond coronary artery disease.

When interpreting troponin results, at least two measurements over time are needed.

Diagnoses of unstable angina are reducing due to high-sensitivite troponin assays.

Safer alternatives for coronary angiography in suspected myocardial infarction seem to be coming available.

\section{Abbreviations:}

ACS: Acute Coronary Syndrome; AMI: Acute Myocardial Infarction; CAG: Coronary Angiography; CCTA: Cardiac CT-
Angiography; CRP: C-Reactive Protein; CCU: Coronary Care Unit; ECG: Electrocardiogram; GP: General Practitioner; H-FABP: HeartType Fatty Acid-Binding ProteinHs-Ctn: High Sensitive Cardiac Specific Troponin; Hs-Ctnt: High Sensitive Cardiac Specific Troponin T; NPV: Negative Predictive Value; NSTEMI: Non ST-Elevated Myocardial Infarction; NT-Probnp: Amino-Terminal Pro Brain Natriuretic Peptide; Poc: Point-Of-Care; RCA: Right Coronary Artery; SA: Stable Angina; Sst2: Soluble Suppression of Tumorigenicity 2; STEMI: ST-Elevated Myocardial Infarction; UA: Unstable Angina

\section{Introduction}

Patients presenting with new or altered chest pain remain a challenge to diagnose. Acute coronary syndrome (ACS) is a serious condition and one possible cause of the chest pain, but in a majority of cases, other less demanding causes are diagnosed. To distinguish between ACS and other causes is important for general practitioners (GPs) in order to correctly refer patients with ACS to a cardiologist and treat less severe causes in primary care. In secondary care, troponin tests are becoming more and more sensitive. Cardiac damage is therefore easier to detect, however, positive test results in marginal cardiac damage caused by conditions other than coronary artery disease are more common. Thus, interpreting elevated levels of high sensitive cardiac specific troponin (hs-cTn) can be difficult. Moreover, 
the gold standard test (coronary angiography - CAG) is not without risk. Possibly, non-invasive imaging techniques could play a role in these cases of doubt. In three case descriptions, we illustrate these dilemmas and in the discussion we eventually evaluate modern diagnostic tools in ACS.

\section{Three Cases}

Patient $\mathrm{A}$ is a 53 years old male with a history of asthma and heavy smoking (35 pack-years). He consults his GP because of chest pain, a tense feeling in his left arm, shortness of breath, burping and fatigue. These complaints started five days before consultation. The chest pain is persistent but occasionally aggravates, for instance, during his work as a house painter. Vegetative symptoms are absent. Auscultation of the heart and lungs is normal. Blood pressure is $145 / 80 \mathrm{mmHg}$, pulse is $70 / \mathrm{min}$ and regular. The GP administers $300 \mathrm{mg}$ of carbasalate calcium and immediately refers the patient to hospital due to suspected ACS. During the waiting period for the ambulance, an ECG is recorded in order to accelerate triage in case of an ST-elevated myocardial infarct (STEMI). However, this ECG reveals no abnormal findings.

Upon arrival at the coronary care unit (CCU), plasma high sensitive cardiac specific troponin $\mathrm{T}$ (hs-cTnT) is $9 \mathrm{ng} / \mathrm{L}$ (reference value $<14$ $\mathrm{ng} / \mathrm{L}$ ). Administration of sublingual nitroglycerine does not alleviate the patient's complaints. The complaints are considered as being typical for ACS and the patient is hospitalised. An exercise tolerance test does not reveal abnormalities. In view of the maintained low plasma hs-cTnT - the result is unchanged upon measurement 6 hours after the initial measurement - the complaints are regarded as not being of cardiac origin. Therefore, CAG is not performed. The patient's complaints cease spontaneously and he is discharged. Within a week, he will visit his GP for primary prevention.

Patient B is a 54 year old male and visits his GP with complaints in both his left shoulder and left hand, accompanied by nocturnal tingling. These complaints have persisted for three weeks. He has suffered from shoulder complaints for several years, and a cervical hernia nuclei pulposi (HNP) at level C5-C6 seven years earlier, which at the time was treated conservatively. He does not smoke. The complaints show no relation with physical exercise and the patient has no chest pain. Physical examination of the neck, shoulder and arm (inspection, palpation, mobility) is normal. The patient has oppressive pain ventrally on the upper arm and dorsally on the hand. Strength in the upper extremities is normal. The GP makes a working diagnosis of brachialgia, possibly caused by a recurrence of HNP, and prescribes analgesics. He asks the patient to return if the complaints remain.

Ten days later the patient returns with the same complaints and in addition, a sore throat. Two years ago he had been seen at a CCU because of chest and neck complaints; cardiac analysis was negative at this time. A physical examination does not reveal new findings. Inspection of the throat and auscultation of the heart remain without abnormalities. Blood pressure and pulse are normal; the patient is not ill and shows no vegetative signs. The GP considers a cardiac origin of the present complaints, mainly due to the unexplained neck pain, and makes an ECG recording which shows no abnormalities. He decides that the patient should be seen by a cardiologist. In order to determine whether acute referral is needed, he performs a hs-cTnT test via the hospital laboratory. Two hours later plasma hs-TnT is found to be elevated $(29 \mathrm{ng} / \mathrm{L})$, at which time the patient is sent to the cardiologist immediately.
At the CCU, plasma hs-cTnT is still elevated to the same level (29 $\mathrm{ng} / \mathrm{L}$ ). In view of the instability of the chest pain complaints, the patient is hospitalised, and is subjected to a cardiac CT-angiography (CCTA) as part of an ongoing trial. On the basis of the CCTA, both dissection of the aorta and lung embolism can be excluded. However, a stenosis of $90-99 \%$ of the right coronary artery (RCA) is observed. The patient subsequently undergoes a CAG which reveals the stenosis to obstruct the mid part of the RCA between $70-90 \%$. Together these findings lead to the diagnosis non ST-elevated myocardial infarction (NSTEMI). The intervention cardiologist inserts a drug-eluting stent at the level of the stenosis. The patient's complaints dissipate and plasma hs-cTnT normalises soon thereafter. Medication aimed at secondary prevention is prescribed with sublingual nitroglycerine if deemed necessary.

Patient C, a 73 year old female, is suffering from hypertension and diabetes mellitus for which she takes amlodipine $5 \mathrm{mg}$ once daily, hydrochlorothiazide $12.5 \mathrm{mg}$ once daily and metformin $500 \mathrm{mg}$ twice daily. The patient visits the GP with complaints of pain on the left chest that started that same day. At the time of visit these complaints have persisted for 4.5 hours. The pain has spread over the entire left chest from armpit to the lower ribs. There is no pressure pain and no relation with physical exercise or use of the upper extremities. The patient began smoking at the age of 16 . Auscultation of heart and lungs is normal. Blood pressure is $132 / 82 \mathrm{mmHg}$ with a regular pulse of $94 / \mathrm{min}$. There is no fever.

The patient is known to visit her GP seldomly, apart from the preventive check-ups. The GP is unable to interpret the complaints as originating from the chest wall. He administers carbasalate calcium and calls an ambulance to refer the patient to the cardiologist due to complaints suggesting ACS. The ECG shows no abnormalities. At the CCU, plasma hs-cTnT is found to be elevated (32 ng/L). Administration of nitroglycerine sublingually provides no relief. The patient is subsequently hospitalised for further observation. One hour later, the chest pain decreases, but the patient develops a fever and become progressively ill. At recurrent measurements plasma hs-cTnT remains $31 \mathrm{ng} / \mathrm{L}$, while plasma C-reactive protein $(\mathrm{CRP})$ is $268 \mathrm{mg} / \mathrm{L}$ (reference value $<5 \mathrm{mg} / \mathrm{L}$ ). An X-ray of the thorax reveals a small infiltration at the periphery of the right upper lobe, and the patient is treated with antibiotics intravenously. Two days later the patient is sicker and short of breath. A repeat X-ray of the thorax shows pleural effusion on the right side. Thorax drainage is initiated and complaints are relieved that day. Twelve days later the patient leaves the hospital with no more than post infectious fatigue.

\section{Discussion}

If the cause of chest pain is clear, for example, myocardial infarction with or without ST elevations on ECG, (un)stable angina, pericarditis or a non-cardiac cause, adequate therapy is well defined (Table 1) [1-5]. Before this point is reached, GPs and cardiologists are faced with several dilemmas:

\section{GP: ACS or no ACS?}

When there is suspicion of ACS, referral to a cardiologist is evident [6]. However, for every patient with a coronary problem, four patients with similar complaints but not life-threatening causes present to the GP [7]. Nevertheless, 73\% of these patients presenting with chest pain are referred [7]. As ACS cannot be ruled out in most cases by history taking and physical examination, it is not possible for the GP to simply 
refer fewer patients [8]. While typical and atypical chest complaints can be caused by ACS, they can also arise from other conditions such as gastro-intestinal or psychogenous disorders. An ECG is unable to rule out ACS at an early stage, and decision rules such as the HEART- score (History, ECG, Age, Risk factors, Troponin) and GRACE-score (Global Registry of Acute Coronary Events) cannot rule out ACS in primary care. Both scores are validated in secondary, but not in primary care.

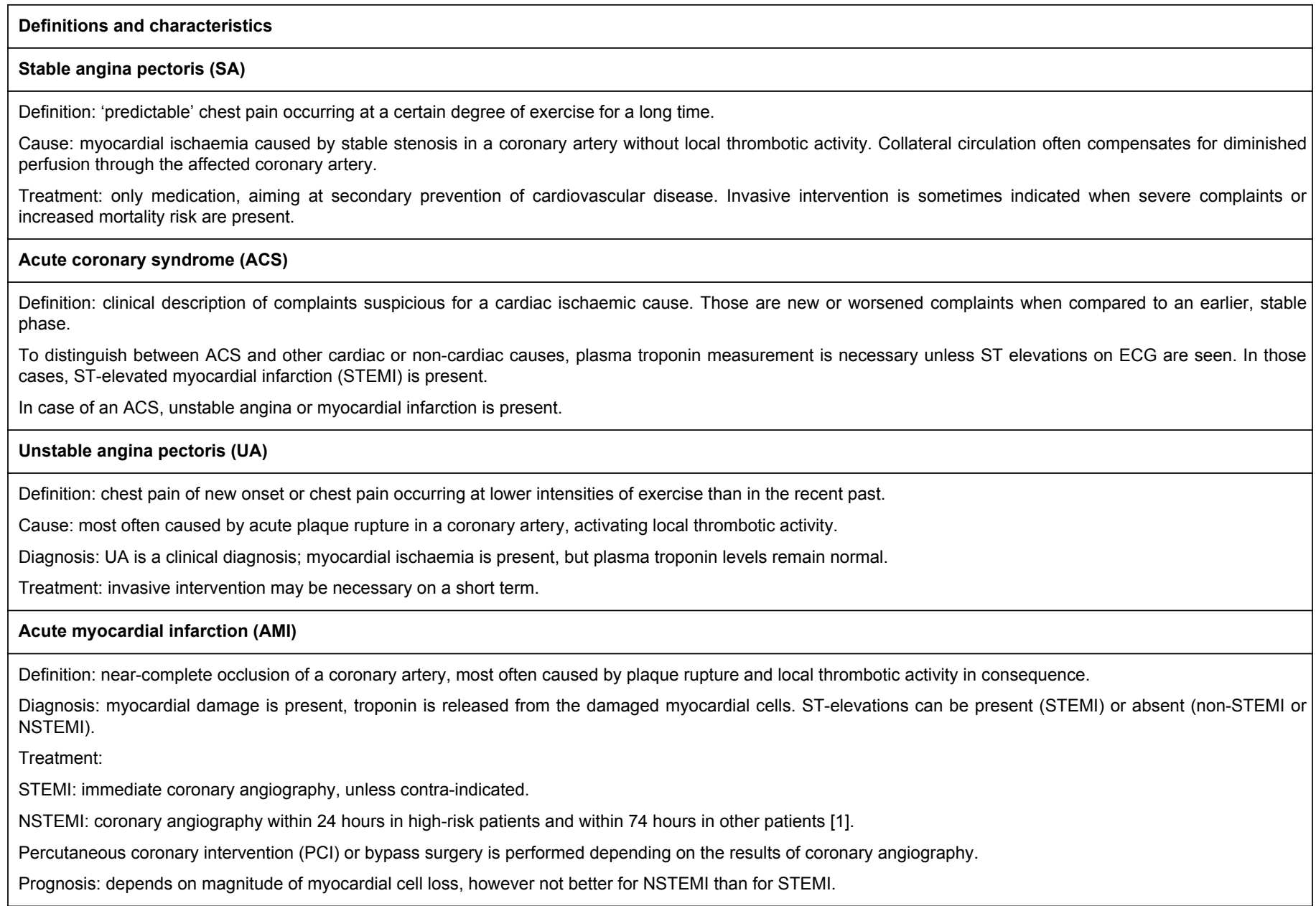

Table 1: Appearances of coronary artery disease [1-4].

Moreover, these scores are partly based on biomarkermeasurements that are not available at the point of care $(\mathrm{PoC})$ in primary care $[3,4]$. In primary care, measuring biomarkers in a laboratory setting when PoC tests are not available as in the case of hscTnT is impracticable due to transport and measuring time. Only in incident cases, when chest complaints are present for several days and there is doubt as to the urgency by which a patient should be referred, a laboratory troponin test can be performed as illustrated above in our case description of patient $\mathrm{B}$.

In future, PoC devices which measure relevant biomarkers might contribute to a more efficient referral process by GPs. Such devices can be based on biomarkers as troponin, heart-type fatty acid-binding protein (H-FABP), copeptin, soluble suppression of tumorigenicity 2 (sST2), amino-terminal pro brain natriuretic peptide (NT-proBNP) or on combinations of two or more of these promising markers [2,9-12]. The first study aiming at such a PoC test (based on H-FABP) in primary care, revealed an insufficient negative predictive value (NPV)
[7]. Future research is aimed at improving such $\mathrm{PoC}$ devices, as the potential cost reduction of a more effective triage is noteworthy [13].

\section{'High sensitive' troponin in diagnosing cardiac ischaemia}

The NPV of contemporary fifth generation hs-cTn tests has increased to $98-99 \%$ [5]. Thus, evidence is growing that cardiac ischaemia can be ruled out within three hours after onset [14]. Moreover, unstable angina (UA) seems to be diagnosed less because of the increasing sensitivity of hs-cTn [5]. In new onset or altered chest pain where hs-cTn is negative, (severe) stable coronary artery disease is becoming increasingly diagnosed instead of UA. Conversely, in cases where hs-cTn is slightly positive, NSTEMI is diagnosed according to the third universal definition of myocardial infarction (Table 2). An elevated hs-cTn value, i.e. above the 99th percentile of a normal reference population, is a strong indicator of myocardial damage and has a very low false-positivity. 


\author{
Criteria \\ Clinical signs of myocardial infarction: \\ appropriate signs and symptoms \\ appropriate ECG abnormalities \\ proof of loss of contractile myocardial tissue on imaging, or \\ an intraluminal thrombus upon coronary angiography
}

Furthermore, a plasma biomarker - preferably troponin - must be elevated above the 99th percentile of a normal reference population (for hs-cTnT: $>14$ ng/L). This elevation is measured at least once from two samples taken at least 3 hours apart. A rise or fall of troponin must be observed between measurements.

In cases where troponin is increased due to reasons other than myocardial infarction, a rising nor falling, slightly elevated troponin is detected at different moments

Table 2: Third universal definition of myocardial infarction [2].

Ischaemia is not the sole cause of myocardial damage, however. Several other diseases also lead to myocardial damage, including pneumonia, pericarditis and left ventricular stress. Using older generation troponin assays, $30 \%$ of patients testing positive had no coronary occlusion [15]. With the current high-sensitivity assays, this percentage is probably even higher. To solve this issue, in the third universal definition of myocardial infarction, AMI is diagnosed when, besides an elevated plasma hs-cTn, a change over time is measured [2]. When such a change is detected, a coronary cause of the cardiac damage is likely (Table 2). The magnitude of the change that is indicative of acute coronary occlusion is still open to debate. In the lower range of troponin results, an absolute change of $7 \mathrm{ng} / \mathrm{L}$ between two measurements is probably indicative of acute coronary disease, whereas in the higher range, a relative change of $20 \%$ is needed [16].

\section{Non-invasive imaging techniques}

Using CT-scanning, coronary artery disease, aortic dissection and pulmonary embolism can be excluded simultaneously. Using cardiac MRI-scanning, diverse causes of myocardial damage can be visualised, among which are infarction, cardiomyopathy and myocarditis. Due to the high NPV of fifth generation hs-cTn assays, cardiac imaging for diagnosing acute coronary occlusions is often unnecessary [17]. In ongoing research, the role of non-invasive imaging techniques as a safe alternative to CAG is being studied in patients presenting with chest pain of recent onset and marginally elevated hs-cTn when there is doubt that ACS is the cause of myocardial damage [18]. The ability of non-invasive techniques to diagnose other causes of myocardial damage seems advantageous.

\section{Back to our patients}

Patient A had typical chest pain complaints. The GP referred him immediately. The pretest probability for ACS at the moment of referral was approximately $20 \%$. Given the period of complaints of several days, one negative hs-cTnT result could sufficiently rule out ACS. The prognosis is favorable [19]. Moreover, complaints were self-limiting and exercise testing was negative.

Patient B was suspected of coronary artery disease by his GP. The GP decided to refer him to a cardiologist within a few weeks, as complaints were present for a significant time. However, since a typical stable pattern was absent, such as pain aggravating on exercise and decreasing while resting, the GP measured a hs-cTn value to rule out ACS. The hs-cTnT turned out to be elevated and the patient was referred immediately. Initially, hs-cTnT was stable over time and criteria of the third universal definition were not met at that time (Table 2). On the other hand, an alternative diagnosis explaining the hs-cTnT result - for example, pericarditis, renal insufficiency or infection - was lacking. On non-invasive cardiac imaging, NSTEMI was diagnosed. The sub-acute course possibly leads to a stable, not rising or falling, plasma hs-cTnT. After stenting, the patient was free of complaints and hs-cTnT returned to normal values. It is currently being studied whether CAG can be safely omitted in similar cases, where hs-cTnT results are difficult to interpret but CT scanning reveals no signs of acute coronary artery disease.

In some patients, further emergency-based analysis reveals an alternative cause of hs-cTn elevation, as is the case in patient C. This case illustrates that marginal elevations of hs-cTn are not on any account pathognomonic for myocardial infarction.

\section{Synopsis}

Based on three cases, we have shown that diagnosing coronary artery disease is becoming less ambiguous; however, both GP and cardiologist are still facing several bottlenecks. In primary care, new diagnostic means are needed to ensure the correct referral of ACSpositive patients and safely eliminate referral of ACS-negative patients. Using contemporary plasma hs-cTnT testing, a cardiologist is able to safely rule out ACS three hours after onset of complaints. Due to the high sensitivity of hs-cTn, unstable angina is being diagnosed less, since in most cases severe stable disease or NSTEMI is present, based on hs-cTn results. The disadvantage of the high sensitivity test is the increasing number of patients with slight elevations of hs-cTn due to causes of myocardial damage other than coronary artery disease. Noninvasive imaging techniques seem to be increasingly valuable when hscTn measurements are inconclusive.

\section{References}

1. Task Force Members, Montalescot G, Sechtem U, Achenbach S, Andreotti F, et al. (2013) 2013 ESC guidelines on the management of stable coronary artery disease: the Task Force on the management of stable coronary artery disease of the European Society of Cardiology. Eur Heart J 34: 2949-3003.

2. Thygesen K, Alpert JS, Jaffe AS, Simoons ML, Chaitman BR, et al. (2012) Third universal definition of myocardial infarction. Eur Heart J 33: 2551-2567.

3. Task Force on the management of ST-segment elevation acute myocardial infarction of the European Society of Cardiology (ESC)1, Steg PG, James SK, Atar D, Badano LP, et al. (2012) ESC Guidelines for the 
Citation: Willemsen RTA, Kietselaer BLJH, Kusters R, Buntinx F, Glatz JFC, et al. (2015) Diagnosing Acute Coronary Syndrome: A Challenge for General Practitioners and Cardiologists. Emerg Med (Los Angel) 5: 242. doi:10.4172/2165-7548.1000242

Page 5 of 5

management of acute myocardial infarction in patients presenting with ST-segment elevation. Eur Heart J 33: 2569-2619.

4. Hamm CW, Bassand JP, Agewall S, Bax J, Boersma E, et al. (2011) ESC Guidelines for the management of acute coronary syndromes in patients presenting without persistent ST-segment elevation: The Task Force for the management of acute coronary syndromes (ACS) in patients presenting without persistent ST-segment elevation of the European Society of Cardiology (ESC). Eur Heart J 32: 2999-3054.

5. Mueller C (2014) Biomarkers and acute coronary syndromes: an update. Eur Heart J 35: 552-556.

6. Rutten FH, Bakx JC, Bruins Slot MHE, Van Casteren BCAM, Derks CJT, et al. (2012) NHG-standaard Acuut coronair syndroom. Huisarts Wet 55: 564-70.

7. Bruins Slot MH, Rutten FH, van der Heijden GJ, Doevendans PA, Mast EG, et al. (2013) Diagnostic value of a heart-type fatty acid-binding protein (H-FABP) bedside test in suspected acute coronary syndrome in primary care. Int J Cardiol 168: 1485-1489.

8. Bruyninckx R, Aertgeerts B, Bruyninckx P, Buntinx F (2008) Signs and symptoms in diagnosing acute myocardial infarction and acute coronary syndrome: a diagnostic meta-analysis. Br J Gen Pract 58: 105-111.

9. Dekker MS, Mosterd A, van 't Hof AW, Hoes AW (2010) Novel biochemical markers in suspected acute coronary syndrome: systematic review and critical appraisal. Heart 96: 1001-1010.

10. Carroll C, Al Khalaf M, Stevens JW, Leaviss J, Goodacre S, et al. (2013) Heart-type fatty acid binding protein as an early marker for myocardial infarction: systematic review and meta-analysis. Emerg Med J 30: 280-286.

11. Collinson P, Gaze D, Goodacre S (2014) Comparison of contemporary troponin assays with the novel biomarkers, heart fatty acid binding protein and copeptin, for the early confirmation or exclusion of myocardial infarction in patients presenting to the emergency department with chest pain. Heart 100: 140-145.
12. Ciccone MM, Cortese F, Gesualdo M, Riccardi R, Di Nunzio D, et al. (2013) A novel cardiac bio-marker: ST2: a review. Molecules 18: 15314-15328.

13. Willemsen RTA, Buntinx F, Winkens B, Glatz JF, Dinant GJ (2014) The value of signs, symptoms and plasma heart-type fatty acid-binding protein (H-FABP) in evaluating patients presenting with symptoms possibly matching acute coronary syndrome: background and methods of a diagnostic study in primary care. BMC Family Practice 15: 203.

14. Bandstein N, Ljung R, Johansson M, Holzmann MJ (2014) Undetectable high-sensitivity cardiac troponin $\mathrm{T}$ level in the emergency department and risk of myocardial infarction. J Am Coll Cardiol 63: 2569-2578.

15. Reichlin T, Hochholzer W, Bassetti S, Steuer S, Stelzig C, et al. (2009) Early diagnosis of myocardial infarction with sensitive cardiac troponin assays. N Engl J Med 361: 858-867.

16. Biener M, Mueller M, Vafaie M, Jaffe AS, Widera C, et al. (2013) Diagnostic performance of rising, falling, or rising and falling kinetic changes of high-sensitivity cardiac troponin $\mathrm{T}$ in an unselected emergency department population. Eur Heart J Acute Cardiovasc Care 2: 314-22.

17. Hoffmann U, Truong QA, Schoenfeld DA, Chou ET, Woodard PK, et al. (2012) Coronary CT angiography versus standard evaluation in acute chest pain. N Engl J Med 367: 299-308.

18. Smulders MW, Kietselaer BL, Das M, Wildberger JE, Crijns HJ, et al. (2013) The role of cardiovascular magnetic resonance imaging and computed tomography angiography in suspected non-ST-elevation myocardial infarction patients: design and rationale of the CARdiovascular Magnetic rEsoNance imaging and computed Tomography Angiography (CARMENTA) trial. Am Heart J 166: 968-75.

19. Mingels AM, Joosen IA, Versteylen MO, Laufer EM, Winkens MH, et al. (2012) High-sensitivity cardiac troponin T: risk stratification tool in patients with symptoms of chest discomfort. PLoS One 7: e35059. 